\title{
Clinical Utility of Longitudinal Measurement of Motor Threshold in Wilson's Disease
}

\author{
Albert Stezin, Nitish Kamble, Ketan Jhunjhunwala, Shweta Prasad, \\ Pramod Kumar Pal
}

\begin{abstract}
This study describes the longitudinal changes of resting motor threshold (RMT) and central motor conduction time (CMCT) in 18 patients with Wilson's disease (WD). The RMT, CMCT, and Global Assessment Scale for Wilson Disease (GAS-WD) were measured at baseline and at follow-up after $12.94 \pm 7.23$ months. There was a significant decrease in the RMT (72.11 \pm 18.62 vs. $63.7 \pm 15.52 \% ; p$-value $=0.002)$ and GAS-WD scores $(14.38 \pm 5.35$ vs. $9.77 \pm 6.47 \mathrm{~ms} ; p$-value $=0.04)$. CMCT did not improve despite chelation therapy. Hence, RMT may serve as a marker of chelation efficacy in WD.

RÉSUMÉ: Utilité clinique des mesures longitudinales du seuil moteur au repos dans le cas de la maladie de Wilson. Cette étude entend décrire les changements longitudinaux affectant le seuil moteur au repos (SMR) et la vitesse de conduction nerveuse motrice (VCNM) chez 18 patients atteints de la maladie de Wilson. Tant le SMR et la VCNM que la Global Assessment Scale for Wilson Disease (GAS-WD) ont été mesurés au départ de l'étude et au moment d'un suivi après $12,94 \pm 7,23$ mois. Une diminution notable du SMR $(72,11 \pm 18,62$ contre $63,7 \pm 15,52 \% ; p=0,002)$ et de la GAS-WD $(14,38$ $\pm 5,35$ contre $9,77 \pm 6,47 \mathrm{~ms} ; p=0,04)$ a pu être observée. En revanche, aucune amélioration sensible de la VCNM n'a été notée en dépit d'une thérapie par chélation. Par conséquent, il se pourrait que le SMR, dans le cas de la maladie de Wilson, puisse être utilisé comme marqueur de l'efficacité de la thérapie par chélation.
\end{abstract}

Keywords: Wilson's disease, Transcranial magnetic stimulation, Cortical excitability, Resting motor threshold, Central motor conduction time

doi:10.1017/cjn.2018.379

Can J Neurol Sci. 2019; 46: 251-254

Transcranial magnetic stimulation (TMS) is a non-invasive technique used to measure the in vivo neurophysiological parameters such as the cortical resting motor threshold (RMT) and central motor conduction time (CMCT). Previous studies have reported poor cortical excitability and prolongation of CMCT in Wilson's disease (WD). ${ }^{1}$ However, the longitudinal changes of these measures and the effect of chelation therapy on them are not clear. The existing literature provides conflicting results. Few studies have reported improvement in CMCT with adequate chelation, whereas other studies, including a study from our group, reported no demonstrable improvement in the cortical excitability. ${ }^{1-4}$ However, these findings were based on recording from a few subjects with varying duration of disease and chelation status. Furthermore, evidence from clinical and neuroimaging studies support that adequate and long-term chelation improves the clinical and MRI abnormalities. ${ }^{5,6}$ Despite the contradictory results from previous studies, we hypothesize that the neurophysiological measures may improve after adequate treatment. In this study of 18 subjects of neurological WD, we investigate the longitudinal changes of RMT and CMCT and also discuss the effect of chelation therapy.

This study was conducted at the National Institute of Mental Health and Neurosciences (NIMHANS), Bangalore. All participants provided informed consent prior to recruitment. The neurophysiological and clinical variables measured included the
RMT, CMCT, and Global Assessment Scale for Wilson Disease (GAS-WD) score. All patients were evaluated longitudinally at two occasions; prior to starting of chelation therapy $\left(\mathrm{RMT}_{\mathbf{1}}\right.$, $\mathrm{CMCT}_{1}$, and $\mathrm{GAS}-\mathrm{WD}_{1}$ ) and in the subsequent follow-up $\left(\mathrm{RMT}_{2}, \mathrm{CMCT}_{2}\right.$, and GAS-WD $)$. After the baseline measurement of $\mathrm{RMT}_{1}, \mathrm{CMCT}_{1}$, and GAS-WD , patients were started on medications. The chelation regimen in subjects consisted of Penicillamine (12-15 mg/kg/day in 2-3 divided doses) and Zinc $(150 \mathrm{mg} /$ day of elemental zinc in 3 divided doses $){ }^{5}$ All medications were stopped for at least 24 hours to allow wash-out of the drug. The demographic details and drug profile of patients are provided in Table 1.

The recommendations of the IFCN committee were followed for all TMS measurements. ${ }^{7}$ Measurements were obtained using a Magstim 200 stimulator and a hand-held, figure-of-eight coil while the subject relaxed in a comfortable chair in a quiet room. Two $\mathrm{Ag}-\mathrm{AgCl}$ electrodes, arranged in a belly-tendon montage

From the Department of Neurology, National Institute of Mental Health \& Neurosciences (NIMHANS), Bangalore, India (AS, NK, KJ, SP, PKP); Clinical Neuroscience, National Institute of Mental Health \& Neurosciences (NIMHANS), Bangalore, India (AS, KJ, SP)

Received July 18, 2018. Final Revisions Submitted October 29, 2018. Date of Acceptance October 31, 2018.

Correspondence to: Pramod Kumar Pal, Department of Neurology, National Institute of Mental Health \& Neurosciences (NIMHANS), Hosur Road, Bangalore 560029, Karnataka, India. Email: palpramod@ hotmail.com 
Table 1: Demography and treatment profile of patients with WD

\begin{tabular}{l|c}
\hline Characteristic & $(\boldsymbol{n}=\mathbf{1 8})$ \\
\hline Gender distribution (M:F) & $11: 7$ \\
\hline Mean age (in years) & $18.9 \pm 8.69$ \\
\hline Duration of disease (in months) & $12.9 \pm 7.23$ \\
\hline Compliance to chelation & $16(88.8 \%)$ \\
\hline Regular treatment & $2(11.1 \%)$ \\
\hline Treatment default & \\
\hline Medications ${ }^{\mathrm{a}}$ & $18(100 \%)$ \\
\hline Penicillamine & $18(100 \%)$ \\
\hline Zinc & $10(55.5 \%)$ \\
\hline Trihexyphenidyl & $6(33.3 \%)$ \\
\hline Baclofen & $3(16.6 \%)$ \\
\hline Levodopa + Carbidopa &
\end{tabular}

${ }^{a}$ Daily dose of medicines (minimum-maximum) - Penicillamine: 500-750 mg; Zinc: 100-150 mg; Trihexyphenidyl: 4-12 mg; Baclofen: 10-20 mg; Levodopa: 100-300 mg; Carbidopa: 25-75 mg. Recording during the follow-up was performed after withholding medication for at least 24 hours.

with the active electrode placed over the belly of the first dorsal interosseus (FDI) and the reference electrode placed on the metacarpophalangeal joint of the index finger, were used to record the motor evoked potentials (MEP).

The optimal "hotspot" was identified by placing the coil at a $45^{\circ}$ angle over the left motor cortex. Stimulation of this "hotspot" elicited motor responses in the contralateral FDI muscle. Relative frequency method was followed for measuring the RMT. From a subthreshold stimulus of $30 \%$ of the maximal stimulator output (MSO), the intensity of the stimulus was increased in increments of 5\% until the TMS consistently evoked MEPs with a peakto-peak amplitude of more than $50 \mu \mathrm{V}{ }^{7}$ The stimulus intensity was sequentially decreased by $1 \%$ of MSO until $<5$ unsatisfactory MEPs were obtained in a trial of 10 recordings. This stimulus intensity plus one was regarded as the RMT. CMCT was determined by motor root stimulation at a suprathreshold stimulus (120\% of RMT). The latency between cortical and motor root stimulation was reported as CMCT (in milliseconds). ${ }^{7}$

Statistical analysis for quantifying significant differences in the RMT, CMCT, and GAS-WD score was performed using Wilcoxon signed rank test for non-parametric data. In subjects with unrecordable RMT, we used the $100 \%$ (MSO) as the imputed RMT for statistical analysis. Improvement in specific clinical symptoms was evaluated using McNemar's test for paired proportions. Correlation (Spearman's correlation) was performed to identify significant associations between the neurophysiological measures and clinical severity score. A threshold of $p<0.05$ after Bonferroni correction for multiple comparisons was considered statistically significant.

The mean age of patients at recruitment was $18.94 \pm 8.69$ years and the mean duration between the first and second recordings was $12.94 \pm 7.23$ months. Among the subjects, $16(88.8 \%)$ patients were on regular chelation therapy, whereas 2 subjects were treatment defaulters. At pre-chelation measurement, MEP was not
Table 2: Clinical and neurophysiological measures at baseline and at follow-up visit in WD

\begin{tabular}{|c|c|c|c|}
\hline Clinical symptom & Pre-chelation & At follow-up & $p$-value \\
\hline Dystonia & $7(38.8 \%)$ & $4(22.2 \%)$ & NS \\
\hline Bradykinesia & $4(22.2 \%)$ & $2(11.1 \%)$ & NS \\
\hline Postural tremor & $6(33.3 \%)$ & $4(22.2 \%)$ & NS \\
\hline Cerebellar signs & $2(11.1 \%)$ & $1(9.0 \%)$ & NS \\
\hline Chorea & $1(9.0 \%)$ & 0 & NS \\
\hline $\mathrm{KF}$ ring & $18(100.0 \%)$ & $18(100.0 \%)$ & NS \\
\hline Pyramidal signs & $8(44.4 \%)$ & $7(38.8 \%)$ & NS \\
\hline Dysarthria & $8(44.4 \%)$ & $5(27.7 \%)$ & NS \\
\hline Drooling of saliva & $4(22.2 \%)$ & $2(11.1 \%)$ & NS \\
\hline Psychosis & $2(11.1 \%)$ & $1(9.0 \%)$ & NS \\
\hline Dysphagia & 0 & 0 & \\
\hline $\begin{array}{l}\text { Intellectual } \\
\text { impairment }\end{array}$ & $4(22.2 \%)$ & $4(22.2 \%)$ & NS \\
\hline GAS-WD score & $14.38 \pm 5.35$ & $9.77 \pm 6.47$ & $0.04 *$ \\
\hline \multicolumn{4}{|c|}{ Neurophysiological measures } \\
\hline $\begin{array}{l}\text { Motor threshold } \\
(\%)\end{array}$ & $72.11 \pm 18.62$ & $63.7 \pm 15.52$ & $0.002 *$ \\
\hline $\begin{array}{l}\text { Central motor } \\
\text { conduction time } \\
\text { (millisec) }\end{array}$ & $7.81 \pm 2.79$ & $8.60 \pm 1.42$ & NS \\
\hline
\end{tabular}

NS $=$ Not significant. Data are based on the presence or absence of symptom. "*” denotes significant $p$-values after correction for multiple comparison.

recordable at $100 \%$ of MSO in three subjects. However, during the follow-up measurement, MEP was recordable in all subjects. On qualitative analysis, 14 subjects had decrease in the RMT and GAS-WD scores. The RMT and GAS-WD score worsened in two subjects who were also treatment defaulters. In yet another two subjects, the RMT and GAS-WD score worsened despite regular therapy. The CMCT value worsened in 11 subjects and improved in 7 subjects. The RMT, CMCT, GASWD score, and specific clinical signs in patients prior to chelation therapy and at the follow-up assessment are provided in Tables 2 and 3.

Statistical analysis revealed a significant decrease in the mean RMT $(72.11 \pm 18.62$ vs. $63.7 \pm 15.52 \%$; corrected $p$-value $=$ 0.002 ) between the first and second assessments. Although statistically significant improvement was not obtained on comparisons of specific clinical features, the overall GAS-WD scores improved significantly $(14.38 \pm 5.35$ vs. $9.77 \pm 6.47$; corrected $p$-value $=0.04)$. The CMCT, however, did not show any significant improvement $(7.81 \pm 2.79$ vs. $8.60 \pm 1.42 ; p$-value $=0.2)$.

There were no significant correlations identified between the RMT, CMCT, and GAS-WD scores at any time point of measurement. However, a significant correlation was obtained between the change in the RMT $\left(\mathrm{RMT}_{1-2}\right)$ and GAS-WD score $\left(\mathrm{GAS}_{-\mathrm{WD}_{1-2}}\right)(r=0.7, p$-value $=0.002)$ after correction for the duration of chelation. There was no significant association of the change in CMCT values and GAS-WD scores.

This study demonstrates the longitudinal improvement in the RMT and GAS-WD scores in patients with WD while on 
Table 3: Longitudinal measurement of resting motor threshold and central motor conduction time in patients with WD

\begin{tabular}{|c|c|c|c|c|c|c|c|}
\hline \multirow[t]{2}{*}{ Patient code/Age/Gender } & \multirow[t]{2}{*}{ Duration of chelation } & \multicolumn{3}{|c|}{ Pre-chelation measurement } & \multicolumn{3}{|c|}{ Measurement during follow-up } \\
\hline & & $\mathrm{RMT}_{1}$ & $\mathrm{CMCT}_{1}$ & GAS-WD 1 & $\mathbf{R M T}_{2}$ & $\mathrm{CMCT}_{2}$ & GAS-WD 2 \\
\hline Patient 1,27 years, Male & 12 months & 90 & 7.11 & 18.00 & 75 & 7.50 & 10.00 \\
\hline Patient 2,12 years, Male & 12 months & NR & - & 10.00 & 80 & 6.90 & 10.00 \\
\hline 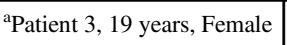 & 12 months & 50 & 7.81 & 10.00 & 85 & 6.11 & 21.00 \\
\hline Patient 4,8 years, Female & 12 months & $\mathrm{NR}$ & - & 28.00 & 71 & 9.57 & 14.00 \\
\hline Patient 5,33 years, Male & 12 months & 73 & 6.25 & 17.00 & 62 & 6.80 & 6.00 \\
\hline Patient 6,18 years, Male & 15 months & 55 & 6.03 & 16.00 & 51 & 8.08 & 11.00 \\
\hline Patient 7,18 years, Female & 26 months & 95 & 13.5 & 14.00 & 85 & 8.60 & 4.00 \\
\hline Patient 8,31 years, Male & 6 months & 70 & 8.02 & 14.00 & 62 & 7.95 & 10.00 \\
\hline${ }^{\text {bPatient }} 9,18$ years, Female & 9 months & 55 & 12.8 & 14.00 & 65 & 10.23 & 14.00 \\
\hline Patient 10,12 years, Male & 36 months & 80 & 8.51 & 14.00 & 55 & 11.2 & 14.00 \\
\hline Patient 11,14 years, Male & 6 months & 67 & 10.5 & 8.00 & 59 & 10.1 & 3.00 \\
\hline Patient 12,26 years, Male & 9 months & NR & - & 10.00 & 79 & 8.11 & 2.00 \\
\hline $\begin{array}{l}{ }^{\text {aPatient }} 13,22 \text { years, } \\
\text { Female }\end{array}$ & 12 months & 67 & 7.60 & 16.00 & 77 & 7.60 & 25.00 \\
\hline Patient 14,19 years, Male & 12 months & 42 & 7.90 & 4.00 & 42 & 9.96 & 2.00 \\
\hline Patient 15,17 years, Female & 12 months & 68 & 8.40 & 17.00 & 39 & 7.82 & 8.00 \\
\hline Patient 16,16 years, Male & 12 months & 48 & 6.75 & 15.00 & 42 & 8.57 & 3.00 \\
\hline Patient 17,17 years, Male & 12 months & 70 & 8.60 & 22.00 & 44 & 10.3 & 11.00 \\
\hline $\begin{array}{l}\text { 'Patient } 18,14 \text { years, } \\
\text { Female }\end{array}$ & 6 months & 68 & 8.15 & 12.00 & 75 & 9.56 & 16.00 \\
\hline
\end{tabular}

$\mathrm{CMCT}=$ Central motor conduction time; GAS-WD = Global Assessment Scale for Wilson Disease score; NR = Non recordable; RMT $=$ Resting motor threshold.

${ }^{\mathrm{a}}$ Treatment defaulters; ${ }^{\mathrm{b}}$ Patient on regular treatment with worsening of RMT and GAS-WD score.

chelation therapy. There was a significant association between the improvement in RMT and GAS-WD scores denoting the potential of RMT measurement as a neurophysiological biomarker in assessing chelation efficacy.

TMS enables the study of the functional properties of the motor cortex and corticospinal tract (CST). The factors affecting the RMT, CMCT, and their mechanism are not well understood. It is believed that RMT is a measure of the excitability of the cortico-cortical fibers projecting to the corticospinal neurons, whereas CMCT depicts the electrical conduction through the CST. $^{1-4,8}$ The RMT changes observed in WD, hence, is a reflection of the cortico-motoneuronal dysfunction causing the decrease in the motoneuron excitability. The motoneuron excitability is influenced by the basal ganglia dysfunction and primary intracortical damage which are further dependent on copper toxicity in WD. ${ }^{1-4,8,9}$ Therefore, chelation therapy may decrease the concentration of circulating copper and improve the clinical abnormalities and basal ganglia dysfunction. This is further supported by a previous study that has demonstrated an inverse relationship between copper concentration and cortical excitability. ${ }^{10}$ It is likely that adequate chelation may improve the RMT by decreasing the copper content and its detrimental sequelae, at least when adequately and timely treated. Furthermore, the changes in the RMT paralleled the changes in GAS-WD score both in treatment defaulters and in subjects who adhered to the chelation regimen. The worsening of RMT and GAS-WD score observed in two subjects while on regular treatment may be due to penicillamine-induced worsening. ${ }^{5}$ Hence, our study demonstrates that longitudinal measurement of RMT may reflect the clinical status of the subject and may have clinical relevance in the evaluation of chelation efficacy in individual subjects. In contrast to our findings, few studies have not observed improvement in RMT following chelation therapy. ${ }^{1-3}$ However, their conclusions were based on the follow-up measurements of one patient in Jhunjhunwala et al. and three subjects in Perretti et al. ${ }^{2,3}$ Nonetheless, it is possible that the timing and adherence to therapy may be key factors influencing improvement in RMT.

In contrast to RMT, lack of improvement in CMCT in our study may suggest irreversible damage to the CST. Previous neurophysiological studies using TMS in different diseases have demonstrated the marked prolongation of CMCT to indicate the loss of neurons or demyelination changes. ${ }^{1-4,8}$ However, mildly prolonged CMCT in our cohort probably may suggest a limited neuronal loss than demyelination. ${ }^{8,11,12}$ The involvement of CST in WD has been established by previous clinical, neurophysiological, and neuroimaging studies. ${ }^{1,4-6}$ However, reversibility of CST involvement is not well known. Longitudinal TMS studies by Perretti et al. (three subjects) and Hefter et al. (six subjects) have reported improvement in CMCT with adequate chelation. $^{3,4}$ The causes for this apparent disparity in our results are uncertain. However, it should be noted that, although not statistically significant, a majority of patients had an improvement of CMCT value from the baseline measurement in this study. It is possible that reversibility of CST involvement may be dependent on how early chelation therapy is instituted. 
To conclude, this study evaluated longitudinal TMS changes in WD and demonstrated the reversible nature of copper-induced neurophysiological changes. Our results imply the reversible nature of cortico-motoneuronal dysfunction of the motor cortex and potentially irreversible nature of CST involvement in WD. However, comprehensive and prospectively designed studies on larger cohorts of patients are necessary to validate our findings.

\section{Statement of Authorship}

AS: Conception, execution, organization of the study, statistical analysis, and writing of first draft.

$\mathrm{NK}$ : Conception, execution of study, and writing of first draft.

KJ: Conception,organization, and execution of the study.

SP: Organization and critical review.

PKP: Conception, design, organization of the study, review, and Critique.

\section{Disclosures}

AS, KJ, NK, SP, and PKP have nothing to disclose.

\section{REFERENCES}

1. Bembenek JP, Kurczych K, Czlonkowska A. TMS-induced motor evoked potentials in Wilson's disease: a systematic literature review. Bioelectromagnetics. 2015;36:255-66.

2. Jhunjhunwala K, Prashanth DK, Netravathi M, Nagaraju BC, Pal PK. Alterations of cortical excitability and central motor conduction time in Wilson's disease. Neurosci Lett. 2013;553:90-4.
3. Perretti A, Pellecchia MT, Lanzillo B, Campanella G, Santoro L. Excitatory and inhibitory mechanisms in Wilson's disease: investigation with magnetic motor cortex stimulation. J Neurol Sci. 2001;192:35-40.

4. Hefter H, Roick H, Von Giesen HJ, et al. Motor impairment in Wilson's disease. 3: the clinical impact of pyramidal tract involvement. Acta Neurol Scand. 1994;89:421-8.

5. Roberts EA, Schilsky ML. Diagnosis and treatment of Wilson disease: an update. Hepatology. 2008;47:2089-111.

6. Kim TJ, Kim IO, Kim WS, et al. MR imaging of the brain in Wilson disease of childhood: findings before and after treatment with clinical correlation. AJNR Am J Neuroradiol. 2006;27: 1373-8.

7. Rossini PM, Burke D, Chen R, et al. Non-invasive electrical and magnetic stimulation of the brain, spinal cord, roots and peripheral nerves: basic principles and procedures for routine clinical and research application. An updated report from an I.F.C.N. Committee. Clin Neurophysiol. 2015;126:1071-107.

8. Kobayashi M, Pascual-Leone A. Transcranial magnetic stimulation in neurology. Lancet Neurol. 2003;2:145-56.

9. Trompetto C, Avanzino L, Marinelli L, et al. Corticospinal excitability in patients with secondary dystonia due to focal lesions of the basal ganglia and thalamus. Clin Neurophysiol. 2012;123: 808-14.

10. Tecchio F, Assenza G, Zappasodi F, Mariani S, Salustri C, Squitti R. Glutamate-mediated primary somatosensory cortex excitability correlated with circulating copper and ceruloplasmin. Int $\mathbf{J}$ Alzheimers Dis. 2011;2011:292593.

11. Yook SW, Park SH, Ko MH, Seo JH. Motor evoked potentials of the upper extremities in healthy children. Ann Rehabil Med. 2011; 35:759-64.

12. Jaiser SR, Barnes JD, Baker SN, Baker MR. A multiple regression model of normal central and peripheral motor conduction times. Muscle Nerve. 2015;51:706-12. 